\title{
What is the optimal cardiac screening for asymptomatic transthyretin gene mutation carriers?
}

\author{
Sang-Geon Cho, MD, PhD, ${ }^{\mathrm{a}}$ Hyung Yoon Kim, MD, ${ }^{\mathrm{b}}$ and Hee-Seung Bom, MD, \\ $\mathrm{PhD}, \mathrm{FANMB}^{\mathrm{C}}$ \\ a Department of Nuclear Medicine, Chonnam National University Hospital, Gwangju, Republic of \\ Korea \\ b Department of Cardiology, Chonnam National University Hospital, Gwangju, Republic of Korea \\ c Department of Nuclear Medicine, Chonnam National University Hwasun Hospital, Jeonnam, \\ Republic of Korea
}

Received Nov 13, 2019; accepted Nov 13, 2019

doi:10.1007/s12350-019-01970-y

\section{See related article, pp. 1949-1957}

In this issue of the Journal of Nuclear Cardiology, Minutoli F. and colleagues elegantly showed that Tc99m 3,3-diphosphono-1,2 propanodicarboxylic acid (DPD) scan is very sensitive in the detection of cardiac involvement for asymptomatic subjects who carry transthyretin (TTR) gene mutation. ${ }^{1}$ Tc-99m DPD accumulation was shown earlier than ECG, echocardiography and biochemical markers some years before the fulfilment of the current diagnostic criteria for cardiac amyloidosis (CA). More interestingly, those subjects who showed cardiac accumulation of Tc-99m DPD eventually had signs of clinical worsening. These findings are clinically important and have a direct impact on the management of asymptomatic subjects with TTR gene mutation. Those who show positive Tc99m DPD scan among asymptomatic TTR gene mutation carriers may be candidates for early therapeutic approaches.

The optimal screening for TTR gene mutation carriers has not yet been established. The prevalence of TTR gene mutation is known to vary by region ${ }^{2}$ while its

Reprint requests: Hee-Seung Bom, MD, PhD, FANMB, Department of Nuclear Medicine, Chonnam National University Hwasun Hospital, 322, Seoyang-ro Hwasun-eup, Hwasun-gun, Jeonnam 58128, Republic of Korea; henryhsbom@gmail.com

J Nucl Cardiol 2021;28:1958-60.

1071-3581/ $\$ 34.00$

Copyright (c) 2019 American Society of Nuclear Cardiology. penetration rate is unknown. Some experts suggest screening for TTR CA in several specific clinical situations ("red flags"), including suspicious and/or highrisk features for TTR CA on echocardiography, cardiac magnetic resonance, and electrocardiogram, and clinically demonstrated neuropathic signs. ${ }^{2}$ However, these warning signs indicate that TTR CA or systemic amyloid deposition has already become clinically apparent. They do not directly reflect actively ongoing cardiac amyloid deposition and are not feasible for early detection of subclinical amyloidosis. Regarding the several therapeutic options that are getting clinical relevance, ${ }^{3-5}$ earlier detection of those at high-risk of TTR CA development is of extreme importance.

The study by Minutoli et al. ${ }^{1}$ sheds lights on the screening of CA development in TTR gene mutation carriers before phenotypic cardiac changes. According to the study data, positive cardiac Tc-99m DPD uptake at the baseline or 2-year follow-up invariably led to clinical TTR CA within several years, and as soon as 1 year later for diastolic dysfunction $(\mathrm{E} / \mathrm{A}<1)$. Considering that it took 5 years or less (median: 2 years) from positive cardiac DPD uptake to the development of symptomatic heart failure, positive cardiac DPD uptake can be deemed to represent rapidly ongoing cardiac amyloid deposition, which precedes the clinical manifestation of TTR CA. Consistent results were obtained with other bone-seeking agents, where their cardiac uptake was considered to occur before clinical manifestations of TTR CA. ${ }^{6,7}$ Based on these results, we may recommend cardiac screening with bone scintigraphy to TTR gene mutation carriers upon the detection of the mutation, even if no suspicious cardiac findings are present. It will assist the early application of therapeutic 


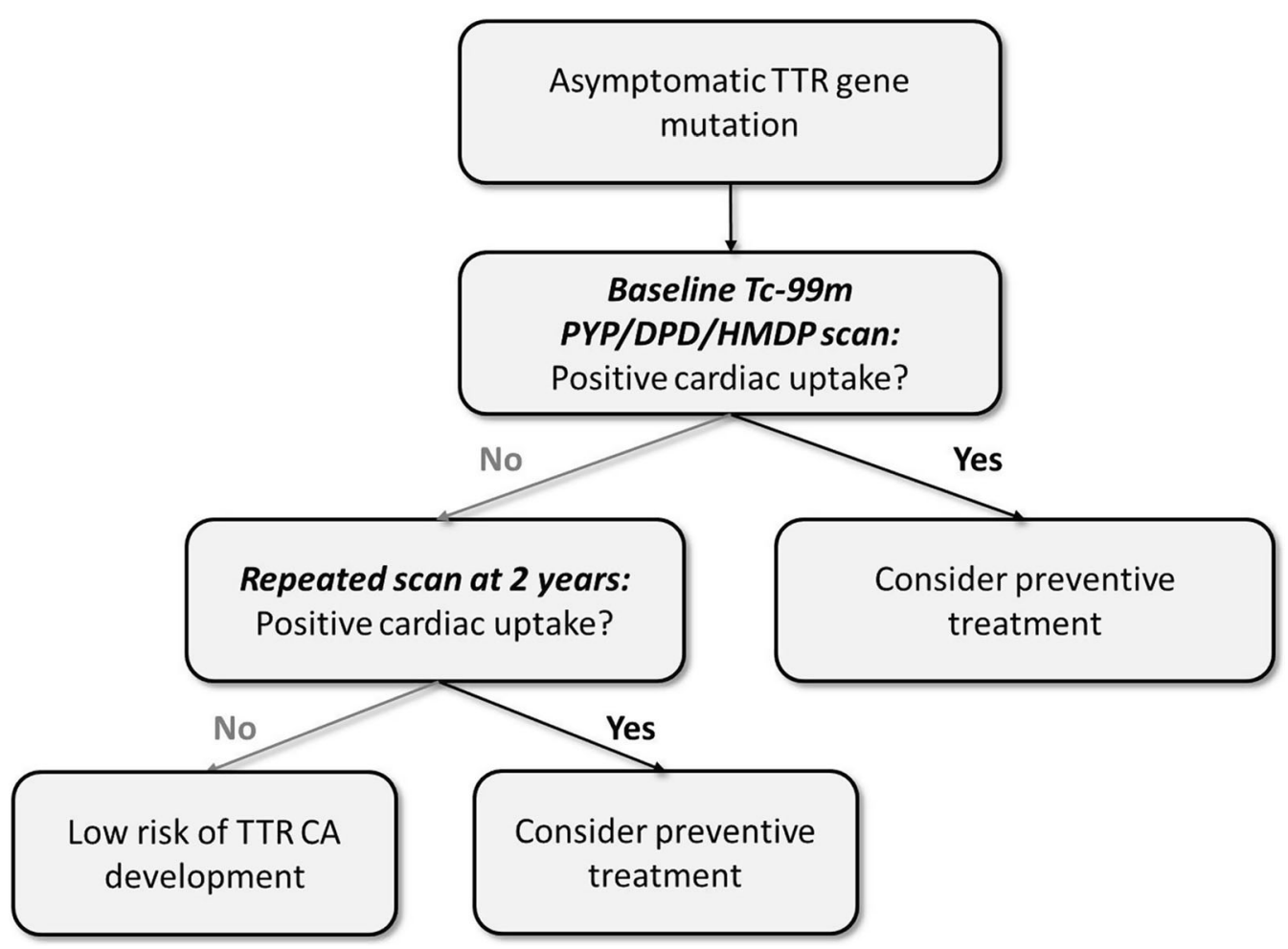

Figure 1. Suggested cardiac screening workflow for TTR gene mutation carriers. TTR, transthyretin; $P Y P$, pyrophosphate; $D P D$, 3,3-diphosphono-1,2 propanodicarboxylic acid; $H M D P$, hydroxymethylene diphosphonate.

agents interrupting the formation and cardiac deposition of amyloid. It is also notable that Tc-99m pyrophosphate (PYP), DPD, and hydroxymethylene diphosphonate (HMDP) have high sensitivity $(97 \% \text { to } 100 \%)^{8-10}$ in detecting TTR CA, while Tc-99m methylene diphosphonate (MDP) may not be equally sensitive. ${ }^{11}$ Therefore, Tc-99m PYP, DPD or HMDP should be preferred to MDP in the screening of TTR gene carriers.

The most notable strength of this study is its longitudinal nature, making its claims even more important with respect to TTR CA screening. Recently, expert consensus recommendations have been announced by multiple societies. ${ }^{12,13}$ The recommendations categorized repeated bone scintigraphy to be appropriate in the screening of asymptomatic TTR gene mutation carriers, however, the indications and suggested interval were not addressed. In this study, among the patients without cardiac uptake on the baseline Tc-99m DPD scan, some showed positive cardiac uptake at the 2-year follow-up scan $(2$ out of $8 ; 25 \%)$. They eventually developed echocardiographic/electrocardiographic abnormalities and symptomatic heart failure no later than 4 years after the baseline scan. Of interest, none of those with negative cardiac uptake on both the baseline and 2-year Tc$99 \mathrm{~m}$ DPD scan became symptomatic throughout the follow-up period ( $\sim 8$ years). Based on these results, at least a serial Tc-99m DPD scan at 2 years after mutation detection should be mandatory even if the baseline scan is negative. In addition, a negative Tc-99m DPD scan at 2 year may imply no TTR CA development within the next several years. Negative cardiac uptake on 2-year serial Tc-99m DPD scan may indicate that cardiac amyloid is not, or is very slowly being, deposited. This result suggests a low likelihood of rapid TTR CA development (Figure 1).

How do we utilize bone scintigraphy for TTR CA management? Regarding the initial diagnosis, the diagnostic accuracy of bone scintigraphy for detecting TTR CA has been well proved. ${ }^{14}$ In terms of a longitudinal follow-up, semiquantitative parameters and tomographic imaging may help tracing serial changes in cardiac uptake. However, the interobserver agreement for the visual assessment of planar images was clinically sufficient in this study $(\kappa=0.937)$. A simple binary interpretation of cardiac uptake (positive vs. negative) may be sufficient in the serial follow-up of TTR gene mutation carriers with respect to the prediction of TTR CA development.

It is clear that bone scintigraphy is an excellent imaging tool for the diagnosis and follow-up of TTR 
CA. Although the cost-effectiveness of TTR CA screening with bone scintigraphy is yet to be investigated, it will clearly be empowered by the novel therapeutic agents entering the clinical fields. This study, in such a clinical context, adds even more important value to serial scanning to detect subjects at higher risk of TTR CA development and helps confirm safety in those with serial negative scans.

\section{Disclosure}

This work was supported by Basic Science Research Program through the National Research Foundation of Korea (NRF) funded by the Ministry of Education (NRF2016R1D1A3B01006631).

\section{References}

1. Minutoli F, Di Bella G, Mazzeo A, Laudicella R, Gentile L, Russo M, Vita G, Baldari S. Serial scanning with 99mTc-3, 3-diphosphono-1, 2-propanodicarboxylic acid $\left.{ }^{99 \mathrm{~m}} \mathrm{Tc}-\mathrm{DPD}\right)$ for early detection of cardiac amyloid deposition and prediction of clinical worsening in subjects carrying a transthyretin gene mutation. $J$ Nucl Cardiol 2019.

2. Witteles RM, Bokhari S, Damy T, Elliott PM, Falk RH, Fine NM, Gospodinova M, Obici L, Rapezzi C, Garcia-Pavia P. Screening for transthyretin amyloid cardiomyopathy in everyday practice. JACC Heart Fail 2019;7:709-16.

3. Maurer MS, Schwartz JH, Gundapaneni B, Elliott PM, Merlini G, Waddington-Cruz M, Kristen AV, Grogan M, Witteles R, Damy T, Drachman BM, Shah SJ, Hanna M, Judge DP, Barsdorf AI, Huber P, Patterson TA, Riley S, Schumacher J, Stewart M, Sultan MB, Rapezzi C, ATTR-ACT Study Investigators. Tafamidis treatment for patients with transthyretin amyloid cardiomyopathy. N Engl J Med 2018;379:1007-16.

4. Judge DP, Heitner SB, Falk RH, Maurer MS, Shah SJ, Witteles RM, Grogan M, Selby V, Jacoby D, Hanna M, Nativi-Nicolau J, Patel J, Rao S, Sinha U, Turtle CW, Fox JC. Transthyretin stabilization by ag10 in symptomatic transthyretin amyloid cardiomyopathy. J Am Coll Cardiol 2019;74:285-95.

5. Solomon SD, Adams D, Kristen A, Grogan M, Gonzalez-Duarte A, Maurer MS, Merlini G, Damy T, Slama MS, Brannagan TH, Dispenzieri A, Berk JL, Shah AM, Garg P, Vaishnaw A, Karsten V, Chen J, Gollob J, Vest J, Suhr O. Effects of patisiran, an rna interference therapeutic, on cardiac parameters in patients with hereditary transthyretin-mediated amyloidosis: Analysis of the apollo study. Circulation 2019;139:431-43.

6. Glaudemans AWJM, van Rheenen RWJ, van den Berg MP, Noordzij W, Koole M, Blokzijl H, Dierckx RAJO, Slart RHJA,
Hazenberg BPC. Bone scintigraphy with (99m)technetium-hydroxymethylene diphosphonate allows early diagnosis of cardiac involvement in patients with transthyretin-derived systemic amyloidosis. Amyloid 2014;21:35-44.

7. Haq M, Pawar S, Berk JL, Miller EJ, Ruberg FL. Can tc-99mpyrophosphate aid in early detection of cardiac involvement in asymptomatic variant ttr amyloidosis? JACC Cardiovasc Imaging 2017;10:713-4

8. Perugini E, Guidalotti PL, Salvi F, Cooke RM, Pettinato C, Riva L, Leone O, Farsad M, Ciliberti P, Bacchi-Reggiani L, Fallani F, Branzi A, Rapezzi C. Noninvasive etiologic diagnosis of cardiac amyloidosis using 99mTc-3,3-diphosphono-1,2-propanodicarboxylic acid scintigraphy. J Am Coll Cardiol 2005;46:1076-84.

9. Bokhari S, Castano A, Pozniakoff T, Deslisle S, Latif F, Maurer MS. (99m)Tc-pyrophosphate scintigraphy for differentiating lightchain cardiac amyloidosis from the transthyretin-related familial and senile cardiac amyloidoses. Circ Cardiovasc Imaging 2013;6:195-201.

10. Galat A, Rosso J, Guellich A, Van Der Gucht A, Rappeneau S, Bodez D, Guendouz S, Tissot CM, Hittinger L, Dubois-Rande JL, Plante-Bordeneuve V, Itti E, Meignan M, Damy T. Usefulness of (99m)Tc-HMDP scintigraphy for the etiologic diagnosis and prognosis of cardiac amyloidosis. Amyloid 2015;22:210-20.

11. Yang JC, Fox J, Chen C, Yu AF. Cardiac ATTR amyloid nuclear imaging-not all bone scintigraphy radionuclide tracers are created equal. J Nucl Cardiol 2018;25:1879-84.

12. Dorbala S, Ando Y, Bokhari S, Dispenzieri A, Falk RH, Ferrari VA, Fontana M, Gheysens O, Gillmore JD, Glaudemans A, Hanna MA, Hazenberg BPC, Kristen AV, Kwong RY, Maurer MS, Merlini G, Miller EJ, Moon JC, Murthy VL, Quarta CC, Rapezzi C, Ruberg FL, Shah SJ, Slart R, Verberne HJ, Bourque JM. ASNC/AHA/ASE/EANM/HFSA/ISA/SCMR/SNMMI expert consensus recommendations for multimodality imaging in cardiac amyloidosis: Part 1 of 2-evidence base and standardized methods of imaging. J Nucl Cardiol 2019. https://doi.org/10.1007/s12350019-01760-6.

13. Dorbala S, Ando Y, Bokhari S, Dispenzieri A, Falk RH, Ferrari VA, Fontana M, Gheysens O, Gillmore JD, Glaudemans A, Hanna MA, Hazenberg BPC, Kristen AV, Kwong RY, Maurer MS, Merlini G, Miller EJ, Moon JC, Murthy VL, Quarta CC, Rapezzi C, Ruberg FL, Shah SJ, Slart R, Verberne HJ, Bourque JM. Asnc/ aha/ase/eanm/hfsa/isa/scmr/snmmi expert consensus recommendations for multimodality imaging in cardiac amyloidosis: Part 2 of 2-diagnostic criteria and appropriate utilization. J Nucl Cardiol 2019. https://doi.org/10.1016/j.cardfail.2019.08.002.

14. Treglia G, Glaudemans AWJM, Bertagna F, Hazenberg BPC, Erba PA, Giubbini R, Ceriani L, Prior JO, Giovanella L, Slart RHJA. Diagnostic accuracy of bone scintigraphy in the assessment of cardiac transthyretin-related amyloidosis: A bivariate meta-analysis. Eur J Nucl Med Mol Imaging 2018;45:1945-55.

Publisher's Note Springer Nature remains neutral with regard to jurisdictional claims in published maps and institutional affiliations. 